\title{
Cultura e instituições de saúde: estudando a participação de traços culturais da sociedade brasileira no processo de trabalho de serviços de atenção básica
}

\author{
Culture and health serviçes: studying the participation \\ of cultural traits of Brazilian society \\ in the work process of primary healthcare services
}

Alessandra Maria Silva Pinto ${ }^{1}$

Alberto Lopes Najar ${ }^{2}$

${ }^{1}$ Instituto Brasileiro de Geografia e Estatística. Av. Beira Mar 436/9, Castelo. 20.021-060 Rio de Janeiro RJ.

alessandra.pinto@ibge.gov.br ${ }^{22}$ Departamento de Ciências Sociais, Escola Nacional de Saúde Pública, Fundação Osvaldo Cruz

\begin{abstract}
The analysis of institutions is a widely researched area of health. The culture of organizations is understood as a symbolic possibility contained in a larger dimension, called "national culture". This premise justifies the incorporation of the social anthropological approach to the study of organizational culture. This study sought to establish the perceptions of employees of two primary healthcare services in Niterói, State of Rio de Janeiro, regarding commonly used social navigation strategies from the theory developed by Roberto DaMatta. The results showed the relational character associated with the stereotype of the Brazilian people manifested by conflicts arising from the existence of values based on the 'individual' and the 'person'. Among them are the distortions observed between discourse and practice, and the mobilization strategies of social navigation like "making do" - to establish a mediation between the person and the impersonal law. The organization of the services of the Niteroi Family Medical Program apparently sets its employees the concrete challenge of balancing the egalitarian principle that underpins the Unified Health System (SSU) with the set of values upon which personal relations are based in Brazilian society.
\end{abstract}

Key words Culture, Organizational culture, Social navigation, Relational society, Primary healthcare service
Resumo A análise de instituições é assunto amplamente pesquisado na área da saúde. A cultura das organizações é entendida como uma possibilidade simbólica contida em uma dimensão maior, denominada "cultura nacional". Essa premissa justifica a incorporação da abordagem sócio antropológica aos estudos de cultura organizacional. O presente estudo propôs-se a conhecer as percepções de funcionários de dois serviços de atenção básica do município de Niterói/RJ sobre estratégias de navegação social comumente utilizadas - a partir da teoria desenvolvida por Roberto DaMatta. Os resultados evidenciaram o caráter relacional associado ao estereótipo do brasileiro que se manifesta mediante conflitos decorrentes da coexistência de valores baseados no 'indivíduo' e na 'pessoa'. Entre eles destacam-se as distorções observadas entre discurso e prática e a mobilização de estratégias de navegação social - como o "jeitinho" - visando estabelecer uma mediação entre a lei impessoal e a pessoa. A forma de organização dos serviços do Programa Médico de Família de Niterói aparentemente impõe a seus funcionários o desafio concreto de equacionar o princípio igualitário que fundamenta o SUS com o conjunto de valores nos quais se baseiam as relações pessoais na sociedade brasileira.

Palavras-chave Cultura, Cultura organizacional, Navegação social, Sociedade relacional, Serviço de atenção básica 


\section{Apresentação}

Sete horas da noite. Um homem passa mal, acometido por crise hipertensiva. Ele mora numa grande cidade brasileira e precisa recorrer ao SUS. Após atendimento o médico da unidade de pronto atendimento entrega-lhe um formulário de encaminhamento para que a unidade básica faça um diagnóstico preciso e lhe indique tratamento adequado. Diante da falta de indicação sobre que serviço procurar, ele questiona o médico que sugere procurar um próximo de casa.

Chegando ao posto do bairro, é orientado a entrar na fila de marcação para consulta dali a três meses. Então ele pergunta: 'Mas, e o formulário?' 'Não será preciso, já que não "agilizará" seu atendimento'. Angustiado com a demora, ele pede ajuda ao vizinho que trabalha em outro posto e conhece o médico. Dois dias depois é atendido, faz seu cadastro e inicia tratamento. Segundo ele, mais uma vez a história se repete: Isso aqui é o Brasil, mesmo! Ai de mim se não tivesse um amigo; ia "chorar miséria!"

Esta história provavelmente evocará a lembrança de episódios similares, suscitando questões relativas à temática das distorções entre a organização formal do Sistema Único de Saúde (SUS) e o efetivo funcionamento de seus serviços. Por outro lado, o chamado 'campo da saúde coletiva' carece ainda de estudos que apreciem, ponderem e analisem o papel que características culturais da sociedade brasileira têm na dinâmica das instituições de saúde.

O serviço de saúde entendido como fenômeno cultural é resultado da realidade social em que está inserido, cuja analogia é uma 'microssociedade'. Em decorrência dessa inserção na 'sociedade maior' ele comporta uma teia de relações instituídas ao longo de sua história enquanto organização, além de elementos culturais externos ${ }^{1}$.

A 'sociedade maior' deve ser percebida como grupo humano com linguagem de signos aberta e apurada que possibilita sua interação cultural e confere um caráter dinâmico e fluido à noção de cultura. Essa configuração, além de impossibilitar determinismos de qualquer natureza, remete à existência de uma 'margem de manobra' aos seus membros que pode estreitar-se, ampliar-se ou manter-se estável. Esse cenário sugere ainda a existência de áreas de significado 'em aberto', abrindo espaço para o surgimento de comportamentos divergentes e, consequentemente, para a mudança².

Grosso modo, a ideia de cultura parte do princípio que diferenças de comportamento entre indivíduos podem ser explicadas pela história cultural de cada grupo em detrimento das diversidades de natureza biológica ou geográfica ${ }^{3}$. Nessa perspectiva a cultura deriva da faculdade humana do aprendizado e de sua plasticidade. Essa característica redunda na aceitação da dinamicidade subjacente ao conceito, bem como da "[...] permanente possibilidade de destruição de um 'estilo de vida', de uma 'ordem social', ou de um 'equilíbrio cultural”’”.

O entendimento da cultura como objeto de pesquisa implica a formulação de interpretações sobre a realidade com o objetivo de sugerir um 'sistema na persistência': lógica sobre a qual se funda a estrutura imaginativa de determinada sociedade ${ }^{4}$. Todavia cabe precaução nesse exercício sob pena de se propor modelos explicativos acabados que elaboram uma leitura simplista do social. Portanto, a apreensão dos fenômenos culturais deve buscar generalizações em detrimento de esquemas deterministas ou reducionistas ${ }^{2}$.

A análise de instituições é assunto amplamente pesquisado na área da saúde de modo a compreender eventuais implicações da dinâmica organizacional dos serviços sobre o processo de cuidado. Grosso modo, os estudos contemplam aspectos associados à cultura organizacional em unidades hospitalares, privilegiando referencial teórico da Ciência da Administração.

O termo 'cultura organizacional' - e suas variantes - associa elementos de áreas de conhecimento díspares como Ciência da Administração e Antropologia, remetendo respectivamente ao pragmatismo e à racionalidade das organizações empresariais vis-à-vis a um universo simbólico pouco afeito a mensurações e vinculado a valores sociais duráveis.

Entre as críticas à perspectiva proveniente da Ciência da Administração destaca-se o caráter instrumental associado à utilização do termo, identificado como um diferencial competitivo: "[...] em vez de [a cultura organizacional] se tornar um conceito para se acessar a 'realidade' ele se tornou uma variável da realidade"s.

Por outro lado o caráter multifacetado do conceito de cultura oferece elementos que subsidiam a compreensão dos serviços de saúde no contexto abrangente da sociedade brasileira. $\mathrm{O}$ alcance dessa meta requer a consideração de ideologias e representações simbólicas que orientam nossa vida diária, investigando o Brasil da forma que ele efetivamente é ${ }^{6}$. Esse raciocínio corrobora o argumento da existência de uma modernidade brasileira alicerçada em nossos valores e história, sugerindo que a compreensão de 
nossos dilemas priorize significados construídos aqui e que dão forma a nossas instituições ${ }^{7}$.

Estudo realizado em serviço de saúde no Rio de Janeiro identificou, na percepção de profissionais, a materialização de dilemas oriundos da operação no universo multivalorativo característico da sociedade brasileira. Quando chamados a opinar sobre parâmetros utilizados na avaliação e na ascensão de servidores em uma unidade pública de saúde, os profissionais salientam que a manifestação de atitudes universalistas deve ser acompanhada de uma boa rede de relações ${ }^{8}$. Subjacente a esta percepção jaz a lógica de que as regras do jogo não são as mesmas para todos.

Essas considerações suscitaram as seguintes questões:

- Como funcionários de serviços de saúde equacionam no trabalho a impessoalidade e a igualdade no tratamento aos usuários com as relações pessoais de amizade e de parentesco?

- Que estratégias são mobilizadas em situações nas quais é preciso conciliar o cumprimento das regras com sua pessoalização?

\section{Material e métodos}

O campo da pesquisa foi realizado em dois serviços da rede básica de saúde de Niterói/RJ - uma policlínica de especialidades ambulatoriais e um módulo do Programa Médico de Família de Niterói (PMFN), contemplando observações de campo e quinze entrevistas. A escolha da policlínica justificou-se frente a suas atribuições de atendimento a demandas de usuários oriundos de unidades do PMFN por atenção ambulatorial especializada e/ou de referenciá-los a outros níveis do sistema de saúde municipal. Adicionalmente contemplou a pretensão de estudar questões culturais em serviços ambulatoriais.

O roteiro de entrevista foi estruturado em sete eixos temáticos abordando identificação do informante, sua trajetória profissional, significados associados a trabalho/casa, relação com colegas/amigos no trabalho, relação com usuários, estratégias de navegação social, significados associados a família/casa/amigos. Aqui são privilegiadas análises associadas a 'estratégias de navegação social'; subsidiariamente o terceiro eixo temático foi contemplado.

A seleção dos entrevistados ocorreu ao final das conversas, mediante indicação do informante, respeitados dois critérios: fazer parte do quadro de funcionários do serviço e partilhar pontos de vista similares aos do informante. A inclusão deste últi- mo justifica-se frente a possibilidade de vislumbrar o desenho de redes sociais e eventuais valores partilhados. Os nomes dos primeiros entrevistados surgiram em conversas com usuários e situações vivenciadas nas observações em campo.

As entrevistas aconteceram em novembro e dezembro de 2008 em local reservado nas dependências dos serviços mediante agendamento prévio com os informantes. As conversas tiveram duração média de 60 minutos. A ordem de apresentação das perguntas do roteiro propiciou um clima descontraído e informal, favorecendo o desenvolvimento das conversas notadamente em relação às estratégias de navegação social. Grosso modo, a finalização das entrevistas coincidiu com o encerramento das perguntas.

Os dados foram trabalhados mediante análise de conteúdo, utilizando-se o recorte temático proposto no roteiro de modo a privilegiar a coerência temática em detrimento da singularidade de cada entrevista 9 .

O projeto de pesquisa foi previamente autorizado pela Fundação Municipal de Saúde de Niterói, submetido e aprovado, pelo Comitê de Ética em Pesquisa da Escola Nacional de Saúde Pública Sergio Arouca. Os nomes dos informantes foram substituídos para salvaguardar sua identidade.

\section{Resultados e discussão}

Para DaMatta um dos aspectos mais vigorosos do chamado dilema brasileiro é a “[...] trágica oscilação entre um esqueleto [...] de leis universais cujo sujeito era o indivíduo e situações onde cada qual se salvava e se despachava como podia, utilizando [...] seu sistema de relações pessoais $[\ldots]]^{\prime 10}$. O resultado disso é um sistema social dividido e/ou equilibrado entre duas unidades básicas: o sujeito das leis universais e o sujeito das relações sociais.

Nesse cenário o jeitinho constitui recurso de operação no sistema, particularizando a norma geral e abstrata. Este 'modo e/ou estilo de realizar' - com um quê de cantada e harmonização de interesses aparentemente opostos - possibilita vislumbrar o mapa de navegação social ${ }^{10}$. Essa expressiva capacidade de negociação constitui vantagem comparativa, já que humaniza as situações, permitindo sua compreensão contextualizada. O reconhecimento da relevância dessa matriz reflexiva - centrada em aspectos mais abrangentes da sociedade brasileira - motivou a tentativa de vislumbrar a alma brasileira no modus operandi do SUS. 
A compreensão do serviço de saúde enquanto realidade social integrada por múltiplos aspectos - econômico, jurídico, cultural, etc. - implica sua divisão e abstração, seguidas do esforço interpretativo de recomposição do todo ${ }^{11}$. Já a apreensão de sua dimensão cultural demanda reconhecimento de estruturas que sustentam relações, valores e significados construídos por seus membros. Essa dinâmica é dada pela coexistência de relações sociais externas e internas ao serviço, bem como das interações entre ambas.

A abordagem damattiana fundamenta-se, entre outros, na dicotomia existente entre casa e rua - descrita originalmente por Gilberto Freyre $^{12,13}$ - para a definição do Brasil como sociedade relacional. Segundo essa interpretação a sociedade brasileira é um universo social cuja complexidade é dada por sua segmentação em três espaços sociais: casa, rua e outro mundo. Aqui são abordados apenas casa e rua. A noção de 'espaço social' assume a condição de área cosmológica que contém "[...] entidades morais, esferas de ação social, [...] domínios culturais institucionalizados [...] capazes de despertar emoções, reações, leis, orações, músicas e imagens esteticamente emolduradas e inspiradas" 14 .

Nos domínios da casa e da rua as relações sociais são ordenadas por diferentes valores. Grosso modo, casa é o universo onde predominam a família, as relações hierárquicas e os papéis sociais previamente definidos. A rua em oposição é o domínio das relações impessoais que a todos iguala, trabalho e anonimato, não havendo espaço para atualização de ideais hierárquicos ${ }^{15}$.

As categorias pessoa e indivíduo - conceitos amplamente utilizados na pesquisa antropológica - agregam valores associados respectivamente à casa e à rua. $\mathrm{O}$ indivíduo - elaboração ocidental no contexto de nascimento do capitalismo - fixa regras do mundo em que vive produzindo ideais individualistas e igualitários. Já a noção de pessoa evoca o ser social com papéis previamente definidos e hierarquizados pela sociedade em que se insere. Sua incompletude justifica o estabelecimento de relações de reciprocidade e complementaridade ${ }^{15,16}$.

A configuração - dada pela coexistência de valores associados a indivíduo e pessoa - é denominada sociedade relacional. O relativismo jaz na permanente possibilidade de transformação de uma situação em outra, decorrente da mobilização desses códigos valorativos distintos, não configurando um eixo ideológico único e tampouco fixo ${ }^{5,14,15}$.

Traços desse caráter relacional vislumbrados nos discursos analisados permitem entrever con- tribuições possíveis a compreensão do serviço de saúde.

\section{Discursos sobre regra e exceção}

Inicialmente ressalta-se que a noção de regra utilizada remonta ao conjunto de princípios produzidos e dominados pelos sujeitos de modo mais ou menos consciente e que orientam seu comportamento social, contendo normas jurídicas formalmente descritas e outras legitimadas pelos costumes do grupo ${ }^{17}$.

As falas sobre regras associam-nas ao objetivo maior de ordenar a vida em sociedade, sendo seu descumprimento associado à desordem e ao caos social: "[...] a gente tem que ter regras pra viver, $[\ldots]$ não pode sair vivendo por viver $[\ldots]$ ". A ordenação da sociedade a partir de normas constitui ainda estratégia que assegura condição de igualdade entre indivíduos.

Já os discursos sobre flexibilização das regras traduzem a dinâmica de operação do universo social brasileiro dada por nosso caráter relacional. Este possibilita permanente transformação de um acontecimento em outro, conforme sua avaliação esteja pautada por códigos valorativos associados ao indivíduo ou à pessoa.

A lógica implícita é que pessoas são portadoras de singularidades, traduzidas em comportamentos diferenciados e eventualmente em confronto com a regra. Indivíduos - considerados 'iguais' para a lei - vivenciam dramas particulares que os diferenciam e humanizam, justificando a flexibilização da regra impessoal. Esta dinâmica permite a atualização do ideário individualista com uma série de compensações: o que a lei impessoal nega por um lado é facultado pelo acionamento de relações pessoais ${ }^{14}$.

A ideia de 'exceção' surgiu de forma implícita e explícita nas falas. Mesmo em discursos cujos valores igualitários são enfatizados ela está presente, sugerindo que a flexibilização da regra é recurso necessário para se operar no universo social brasileiro: "[...] as leis foram feitas para serem cumpridas. Senão a gente [...] Vai viver numa desordem [...] É óbvio que você, às vezes, não vai seguir... À risca tudo [...] Mas você tem que tentar [abaixa o tom de voz] andar... No melhor caminho possível".

A leve oscilação na voz de Helena parece indicar o conflito motivado pelo discurso igualitário combinado à pessoalização da regra, resumindo a tentativa de estabelecer uma relação entre o universo do indivíduo e da pessoa ${ }^{14}$.

Entre as justificativas para o descumprimento de regras são destacadas distorções entre re- 
gra e prática e malandragem típica do brasileiro traduzida no 'jeitinho'. As primeiras reproduzem o permanente conflito em voga na sociedade brasileira, dado pela formalidade das leis impessoais e a informalidade das relações pessoais.

As referências ao 'jeitinho' como justificativa para o descumprimento de leis evidenciam uma versão condenatória da prática decorrente de sua ambiguidade. Não é possível definir claramente o limite a partir do qual a utilização do 'jeitinho' deixa de ser justificada para a resolução de demandas legítimas do usuário e passa a justificar a obtenção de privilégios pessoais.

A tendência de avaliação negativa parece derivar ainda da associação estabelecida pela mídia entre 'jeitinho’ e corrupção. Todavia o 'jeitinho’ e o malandro - seu usuário típico - representam posições intermediárias na cosmologia brasileira, promovendo a interseção de universos sociais opostos: o legal, o honesto e o positivo com o ilegal, o desonesto e o negativo ${ }^{5}$.

Finalmente os discursos sugerem que a flexibilização da regra limita-se a situações em que a infração não vai frontalmente de encontro à norma, evidenciando outra faceta do dilema brasileiro: a concepção de que a lei é um instrumento para correção e reinvenção da sociedade através da substituição de valores ditos 'arcaicos' por outros 'modernos'.

Este cenário sugere uma situação paradoxal dada pela existência de arcabouço jurídico sem correspondência com a prática social. A lei adquire status de instrumento meramente formal e reproduz um ciclo vicioso em que se multiplicam regulamentos altamente específicos que tentam prever todas as situações práticas, mediadas e flexibilizadas por uma infinidade de 'jeitinhos' e de relações pessoais. É a velha máxima: 'as leis são feitas para não serem cumpridas'.

DaMatta $^{15}$ argumenta que o fato de confiarmos tanto na força fria da lei como instrumento de mudança do mundo faz com que inventemos tantas leis e as tornemos inoperantes, engendrando outro dilema: a excessiva normatização desvinculada da prática.

\section{Discursos sobre a temática da reciprocidade}

O conceito de reciprocidade aqui utilizado descrito por Marcel Mauss ${ }^{18}$ - remete a noções como dádiva e obrigatoriedade da retribuição. A retribuição, contida na tríplice obrigação 'dar, receber e retribuir', constitui estratégia de estabelecimento de relações, sendo a dádiva expressão material dos vínculos estabelecidos ${ }^{19}$.
Discursos associados à reciprocidade variam entre a direta e a difusa. A reciprocidade direta tem origem na concessão de um favor e se direciona a quem proporcionou a ajuda: "[...] Você faz um favor pra alguém e a pessoa na primeira oportunidade [...] vai fazer pra você [...] se você estiver precisando de uma coisa que esteja ao alcance ele vai te ajudar".

Já a reciprocidade difusa é caracterizada pela retribuição sem destinatário definido: "[...] se você ajudar hoje, no dia que você precisar [...] vai ser ajudada [...] Hoje você precisa... Amanhã você ajuda... Depois de amanhã você é ajudado. Eu acho que $[. .$.$] O que acontece comigo pode acon-$ tecer com você $[\ldots]$ "...

A reciprocidade difusa vincula-se ao sentimento de imponderabilidade da vida: qualquer pessoa está sujeita a passar por situações que demandarão a ajuda de outrem, sendo impossível saber quando esta se fará necessária. Condição que iguala as pessoas e motiva o caráter difuso da retribuição.

As percepções negativas acerca da reciprocidade associam-na a situações com privilégio de alguém em prejuízo de outrem. É nesse domínio simbólico que o ‘jeitinho’ está inserido. Provavelmente a variedade e a frequência de escândalos documentados pela mídia envolvendo nossas instituições políticas e sua associação com o 'jeitinho' justificam a visão pejorativa que os informantes têm daquela prática.

Barbosa $^{5}$ salienta que o sentimento de reciprocidade direta - motivado pelo 'favor' - constitui elemento aglutinador da sociedade, propiciando homogeneização das diferenças sociais. Num exemplo, adaptado da fala de um entrevistado, alguém da comunidade onde se localiza o serviço do PMFN acaba de falecer e não pôde ser enterrado porque não possuía carteira de identidade. Diante da urgência um funcionário aciona seu conhecido que consegue agilizar a confecção do documento. Nessa situação o 'favor' desempenhou papel fundamental minimizando contratempos e agilizando a resolução do problema.

Seguindo esse raciocínio na reciprocidade difusa - originada pelo ‘jeitinho' - o potencial tenderia a aumentar, já que a retribuição pelo 'jeitinho' pode beneficiar um conhecido ou desconhecido em igual probabilidade. Nessas situações um relacionamento de longa duração não determina o beneficiário da retribuição. Além disso, o potencial aglutinador da prática jaz na possibilidade do estabelecimento de vínculo entre quem dá o ‘jeitinho’ e qualquer anônimo que o receba. 
Estratégias de navegação social e 'jeitinho’: percepções subjacentes a situações cotidianas

O contexto brasileiro - dado pela permanente possibilidade de trânsito entre códigos valorativos diversos - engendra o campo social do 'jeitinho', estratégia de navegação social mobilizada para relacionar a lei impessoal e as pessoas a ela submetidas ${ }^{10,15}$.

Entre os elementos presentes nas situações de 'jeitinho', destacam-se a existência de impasse criado a partir de demandas do indivíduo sob o jugo de regras impessoais, o caráter de imprevisibilidade do acontecimento e a necessidade de mobilização de recursos individuais como criatividade, esperteza, simpatia e 'jogo de cintura' para sua resolução ${ }^{5}$.

Com a apresentação de situações classificadas na Pesquisa Social Brasileira como 'jeitinho'20 pretendeu-se conhecer a percepção dos informantes sobre estratégias de navegação social habitualmente utilizadas. A existência de demandas ordenadas ou não por uma fila, bem como de relações pessoais que redundam em algum privilégio, constituem características comuns.

Na percepção dos entrevistados a fila é um ícone de igualdade. Respeitá-la é, portanto, condição determinante para assegurar princípios igualitários. A questão da flexibilização das regras ressurge no contexto em que 'furar a fila' equivale a exceder a regra, sendo enfatizada a necessidade da existência de limites para essa extrapolação.

Nessa perspectiva é aceitável recorrer eventualmente à ajuda de conhecidos para agilizar a resolução de uma situação, sendo essa prática relativamente comum. Entretanto é inaceitável que a ajuda caracterize 'furar a fila' concretamente formada, desrespeitando o direito dos que chegaram primeiro e estão esperando, em decorrência de amizade ou conhecimento.

Estratégias de ação exigidas pela vivência em um universo multivalorativo emergem frequentemente das falas de entrevistados que mantêm contato direto com os usuários. Não obstante a existência de contextos que justificam privilegiar determinadas pessoas na fila é ressaltada a necessidade de transparência para evitar conflitos: “[...]Tem pessoas marcadas [...] Aí chega uma pessoa passando mal[...] Eu comunico: 'Gente. Essa senhora tá sentindo mal. Não vai poder esperar todo mundo ser atendido' [...] Acho que nunca me falaram NÃO [...]As pessoas liberam numa boa.[...] vai tudo do jeito que você fala [...]”
Outra característica comum aos discursos refere-se ao tratamento dispensado aos que estão na fila: como sua ordem associa-se a um direito adquirido, o funcionário solicita permissão para cessão desse direito em detrimento de utilizar o relativo poder de que dispõe para alterar a ordem e privilegiar alguém.

Quando o potencial beneficiário do privilégio é um conhecido, os informantes dividem-se entre aqueles que descartam essa possibilidade e os que reconhecem sua existência. Estes alegam que, na condição de o privilegiado ser um conhecido, a situação deve acontecer de forma discreta e obrigatoriamente distante dos expectadores da fila. É possível 'quebrar o galho' de um conhecido, mas essa atitude não deve ser presenciada pelos que estão esperando, sob pena de causar-lhes um sentimento, que identificam em si próprios, de estar sendo enganados, feito de bobos etc.

As situações apresentadas suscitaram lembranças de vivências em que ora estavam no lugar de quem 'fura a fila', ora entre os preteridos por outrem, e ainda na posição de quem privilegia alguém. Os relatos fazem-se acompanhar por sentimentos diversos: constrangimento, quando se colocam no papel de quem privilegia e sensação de estar sendo agredido quando se percebem preteridos. A postura de 'colocar-se no lugar do outro' explica essa multiplicidade de sentimentos, justificando o 'cuidado' dos informantes em relação aos usuários para que eles não sofram embaraços desnecessários.

Os conflitos motivados pela vivência no universo multivalorativo brasileiro adquirem contornos singulares para funcionários do PMFN que residem nas comunidades onde se localiza o serviço. Nessa condição eles mantêm relações pessoais com moradores da comunidade na qualidade de familiares, amigos e/ou conhecidos. Por outro lado o trabalho impõe-lhes a manutenção de relações impessoais na prestação de atendimento a todos os usuários do serviço, independente de eventuais laços de parentesco, amizade e/ou compadrio.

Em decorrência da condição supracitada supõe-se que esses funcionários sejam veementemente persuadidos a estabelecerem estratégias concretas de navegação entre os universos pessoal e impessoal, conforme revela o discurso: “[...] Aqui dentro você é profissional. Então todo mundo[...]É igual [...] tem que separar. Porque [...] As pessoas confundem [...] vai pedir porque é amigo [...] tem que deixar bem claro pro seu amigo porque [...] Tá em jogo [...] outras pessoas [...] Então se ela tá sendo tratada como paci- 
ente porque aquele vai ter privilégios? Só porque é teu amigo? Aí você, naquela hora ali, vai tratar ele de igual para igual".

A estratégia utilizada aqui é verbalizar claramente aos usuários 'amigos e/ou parentes' a separação existente entre ambos os espaços cujas relações são pautadas por códigos valorativos distintos.

Esses funcionários tendem ainda a ser mais rigorosos em relação a concessão de privilégios a parentes e amigos como estratégia para lidar com a grande exposição que vivenciam no trabalho. A necessidade do estabelecimento de estratégias concretas de ação para promover a permanente separação entre os espaços da casa e da rua - onde está o ambiente de trabalho - parece influenciar decisivamente seus discursos. O julgamento das situações apresentadas demonstra estreita associação com as vivências no serviço de saúde, conforme descreve Renata: "[referindo-se a situação em que o conhecido passou a frente na fila do banco] Sem vergonha! [evoca situação semelhante] Eu senti que aquela pessoa tivesse sido privilegiada [...] Me senti desmerecida [...] Ele não é melhor do que eu. Porque passou na minha vez? Eu não tô aqui aguardando? [...] Eu não faço isso com a minha mãe quando chega lá na consulta. Ela chegou lá atrasada. Falei: 'Mãe... 'Cê chegou atrasada! Não vai deixar de ser atendida. Mas vai aguardar um pouquinho' [...] Ela ficou meia hora esperando. Eu faço isso com os outros pacientes, por que eu não vou fazer com a minha mãe?"

A problematização acima não pretende aprofundar questões sobre tema tão complexo como distinções entre discurso e prática, vinculandose apenas ao propósito de realçar características evidenciadas em determinada realidade social. Sua relevância decorre ainda da possibilidade de oferecer um campo fecundo para vislumbrar a dinâmica de serviços que compõem a Estratégia de Saúde da Família - ESF - a partir das práticas sociais de seus integrantes. A similitude entre a ESF e o PMFN, no que se refere à obrigatoriedade do recrutamento de moradores da comunidade onde se localiza o serviço para determinadas funções, impõe àquela política setorial os mesmos desafios postos para alguns informantes deste estudo: equacionar o princípio igualitário que fundamenta a organização dos serviços de saúde do SUS com o conjunto de valores nos quais se baseiam as relações de parentesco, compadrio e amizade na sociedade brasileira.

A temática da relativização ressurge ainda associada explicitamente à influência exercida pela distância na análise das situações: “[...] Quando a gente avalia no todo... Tá tudo errado! Quando avalia individualmente, às vezes aquela pessoa [...] na fila do banco, tá precisando do dinheiro pra resolver uma situação importante [...] Se for avaliar individualmente talvez algumas dessas situações possam ser justificadas. Mas se [...] avaliar no coletivo você tá invadindo o direito do outro né?"

Essa distância implica diferentes perspectivas de observação do mesmo fenômeno, definidas na fala acima como coletivo e individualidade. Há, portanto, dois planos para se avaliar uma situação: mantendo-se certo distanciamento, os fatos são analisados pelo viés da impessoalidade e dos valores igualitários. Sob essa perspectiva as situações expostas estão todas erradas, pois ferem o princípio da igualdade.

Todavia ao se aproximar da situação é possível entrever seus imponderáveis, colocando em perspectiva singularidades da pessoa. Por conseguinte, atitudes consideradas inaceitáveis quando observadas a certa distância tornam-se perfeitamente justificáveis, se considerado seu contexto de ocorrência.

A situação caracterizada por ausência de fila objetivamente constituída suscitou opiniões divergentes. Discursos condenatórios alegam que a inexistência de fila não elimina o fato de que outras demandas foram preteridas pelas do beneficiário. Alguém será privilegiado em decorrência da rede de conhecimentos de que dispõe. Já os defensores argumentam que não há violação dos direitos alheios, pois a fila, de fato, inexiste.

A natureza do documento requerido também influencia a avaliação. Grosso modo, os entrevistados destacam a existência de casos de 'vida ou morte' que justificam o privilégio. Todavia ressalta-se o caráter altamente subjetivo assumido pela definição de 'caso de vida ou morte'. Que limites definem uma situação como sendo de 'vida ou morte'?

\section{Buscando um quadro de referência}

Grosso modo as falas revelam a rapidez com que, ora é mobilizado o código valorativo do indivíduo, ora da pessoa. Em um mesmo assunto é comum a mobilização de argumentos associados a ambos, caracterizando o viés relacional atribuído por DaMatta à sociedade brasileira ${ }^{10,14,15}$. Essa dinâmica confere complexidade ao fenômeno e sinaliza a impossibilidade de sua análise sob perspectiva estática.

A expressão desse caráter relacional sugere ainda desafios e possibilidades ao entendimento 
da dinâmica social brasileira e à configuração que esta assume no âmbito do serviço de saúde, com eventuais implicações no processo de cuidado. Vejamos:

Respondendo a questão sobre o porquê de o Brasil não dar certo, DaMatta aponta a impossibilidade de compreensão da nossa sociedade a partir de um código valorativo hegemônico ou dominante. Não é possível corrigir o mundo público das leis impessoais sem fazer simultaneamente séria crítica às redes de amizade e compadrio - oriundos do espaço social 'casa' - que penetram nossa vida política, institucional e jurídica ${ }^{10}$.

A consideração da 'casa' - conforme descrita por Freyre ${ }^{12,13}$ - como 'fato social total'11 agrega elementos a discussão acima. Fenômenos descritos como 'fato social total' são primordialmente caracterizados por sua capacidade de englobar e totalizar outras dimensões da vida social (jurídica, econômica, etc.), implicando uma lógica de operação orientada por código valorativo próprio. Assim a compreensão de nosso universo social requer também a consideração do desenho e dos padrões de comportamento oriundos da casa.

Por conseguinte uma análise abrangente da sociedade brasileira deve associar o idioma da economia e da política veiculado pela rua com a linguagem da casa e da família que também determinam grandemente o comportamento profundo de nosso povo ${ }^{10}$.

Adicionalmente reflexões sobre o Brasil devem considerar, além da correção das distorções em nosso mundo público, o resgate de nossa capacidade de sintetizar, relacionar e conciliar valores como patrimônio altamente positivo: “[...] num mundo que cada vez mais se desencanta consigo mesmo e institui um individualismo sem limites, que reduz os valores coletivos a mero apêndice da felicidade pessoal, a capacidade de [...] deslumbrar-se com a sociedade é algo muito $[\ldots]$ positivo $[\ldots]{ }^{\prime 10}$.

A contextualização dessa discussão no âmbito da saúde faz emergir reflexões interessantes ainda que preliminares. É razoável supor que a flexibilidade para lidar com o imprevisto e o infinito de possibilidades - característicos do brasileiro - favoreçam a concretização da integralidade - conforme definida por Mattos ${ }^{21}$, já que a assunção desse princípio implica recusa do reducionismo e objetivação dos sujeitos, reafirmando a abertura ao diálogo.

\section{Considerações finais}

Inicialmente é preciso considerar que a assunção de nosso caráter flexível e intermediário, além do reconhecimento das estratégias de navegação social como práticas comuns em nossa sociedade não implicam na defesa de posturas corruptas ou privilégios decorrentes de relações pessoais, comumente associadas ao estereótipo do brasileiro. Essa atitude é parte de um processo mais amplo de aproximação e aceitação de nossas singularidades com o propósito de identificar potencialidades e limitações.

Ainda que sociedades igualitárias legitimem valores impessoais em espaços públicos, as relações pessoais persistem em seus ambientes privados. Esse cenário impossibilita que sejam vislumbrados simultaneamente os modos de operação de ambas as éticas. Nesse sentido a sociedade brasileira é paradigmática, pois propicia a vivência, em nível de práticas, dos impasses decorrentes dessa coexistência.

As percepções contraditórias suscitadas pelo ‘jeitinho’ e a reciprocidade são ilustrativas da lógica supracitada. Embora no plano simbólico ambas sejam objeto de severas críticas, são inevitavelmente mobilizadas quando as regras do serviço inviabilizam a resolução de demandas dos usuários consideradas legítimas. A avaliação negativa conferida ao 'jeitinho' e à retribuição decorre do fato de sua utilização se justificar tanto para a obtenção de privilégios como para a resolução de dramas pessoais.

Outra faceta do dilema brasileiro é dada pela concepção da lei como instrumento de correção e reinvenção da sociedade mediante substituição de valores ditos 'arcaicos' por outros 'modernos', redundando na existência de arcabouço jurídico sem qualquer correspondência com a prática social.

Questiona-se ainda se a mobilização de estratégias de navegação social não desestimularia transformações estruturais da realidade social. Ao propiciarem a resolução de impasses no momento em que surgem mediante mecanismos compensatórios, não são criadas condições para transformações mais profundas.

Reconhecendo que a complexidade do tema e a multiplicidade de fatores envolvidos impossibilitam seu desenvolvimento neste espaço, cabe destacar a distância existente entre os direitos dos usuários - formalizados em leis e regulamentos - e o atendimento que lhes é efetivamente oferecido no SUS. Por outro lado, experiências daqueles que vivenciam esse dia-a-dia revelam poten- 
cialidades e dilemas decorrentes da manifestação de nosso caráter relacional. Os casos descritos abaixo ilustram essa lógica de operação.

A primeira situação, vivida durante a coleta de dados para estudo hospitalar do município do Rio de Janeiro, revela os benefícios decorrentes de uma rede de relações pessoais. Naquela unidade etapas devem ser cumpridas visando autorização para a coleta de dados com o propósito de resguardar direitos do serviço e dos pacientes. Até aí, nenhuma novidade: um procedimento coerente e esperado, considerando questões éticas subjacentes. Diante da morosidade do processo e sob risco de comprometimento do cronograma, o pesquisador acionou um conhecido que lhe auxiliasse no trâmite burocrático otimizando o tempo disponível. Surpreendentemente o contato significou a eliminação de maior parte das etapas administrativas e acesso imediato aos dados. Esta história, com infinitas variações, sugere o papel decisivo das relações pessoais na eliminação de etapas formais, que teoricamente deveriam ser seguidas por todos que desejam acessar o serviço.

Por outro lado, a experiência em campo sugere que a pessoalização das relações com o usuário - em determinados contextos - melhora sua relação com o serviço de saúde e, no limite, redunda em atendimento mais humanizado. Considerando-se a existência de uma política setorial com esse objetivo, não seria razoável examinar mais detidamente esse nosso traço cultural e entrever seu potencial de contribuição para o alcance daquela política?

Cabe reiterar ainda o espaço potencial, vislumbrado no âmbito de equipes de Saúde da Família, para a compreensão da lógica e dilemas que perpassam a operação do universo multivalorativo brasileiro. As informações deste trabalho demonstram que a liminaridade decorrente da mobilização de valores pessoais e impessoais, vivenciada por funcionários que residem na comunidade onde trabalham, implica em estratégias concretas para a resolução de impasses no cotidiano.

As considerações acima sugerem possibilidades decorrentes de reflexões suscitadas pela análise dos dados. Na qualidade de ensaios interpretativos devem ser avaliados, criticados e, quiçá, refutados. Finalmente pondera-se que todas as sociedades têm virtudes e dilemas. É preciso que essa perspectiva norteie a compreensão de nossa realidade social, sob risco de uma avaliação simplista e incapaz de reconhecer nossa complexidade constitutiva e nossas potencialidades.

\section{Colaboradores}

Pinto, AMS e AL Najar participaram igualmente de todas as fases de elaboração do artigo desde a concepção, análise dos dados até a escrita do texto propriamente dito. 


\section{Referências}

1. Vaitsman J. Cultura de organizações públicas de saúde: notas sobre a construção de um objeto. Cad Saude Publica [periódico na Internet]. 2000 Set [acessado 2009 mar 13]; 16(3): 847-850. Disponível em: http://www.scielo.br/scielo.php?script=sci_ arttext\&pid=S0102-311X2000000300033\&lng=pt

2. Velho G. O estudo do comportamento desviante: a contribuição da Antropologia Social. In: Velho G, organizador. Desvio e divergência: uma crítica da patologia social. $8^{\text {a }}$. ed. Rio de Janeiro: Jorge Zahar Editora; 2003. p. 11-28.

3. Laraia RB. Cultura: um conceito antropológico. 21 ed. Rio de Janeiro: Jorge Zahar Editora; 2007.

4. Geertz C. O saber local: novos ensaios em antropologia interpretativa. Tradução Vera Mello Joscelyne. 5a ed. Petrópolis: Editora Vozes; 2002.

5. Barbosa L. O jeitinho brasileiro: a arte de ser mais igual que os outros. 10 a ed. Rio de Janeiro: Eselvier; 1992.

6. DaMatta R. Prefácio. In: Barbosa L. O jeitinho brasileiro: a arte de ser mais igual que os outros. $10^{\text {a }}$ ed. Rio de Janeiro: Eselvier; 1992.

7. DaMatta R. O Brasil como morada: apresentação para Sobrados e Mucambos. In: Freyre G. Sobrados e mucambos: decadência do patriarcado rural e desenvolvimento do urbano. 14a ed. revisada. São Paulo: Global; 2003. p. 11-22.

8. Vaitsman J. Gerencialismo, cultura e expectativas entre servidores públicos de saúde. Revista de Administração Pública 2001; 35(1):29-47.

9. Blanchet A, Gotman A. A análise dos discursos. In Blanchet A, Gotman A. A enquete e seus métodos: a entrevista. Tradução de Greice Menezes. Revisão técnica: Maria Luiza Heilborn e Michel Bozon. Mimeo. p. 2-11.

10. DaMatta R. O que faz o brasil, Brasil? Rio de Janeiro: Rocco; 1984.

11. Lévi-Strauss C. Introdução: A obra de Marcel Mauss In: Mauss M. Sociologia e Antropologia com uma introdução à obra de Marcel Mauss de Claude LéviStrauss. Tradução de Lamberto Puccinelli. Volume I. São Paulo: EPU; 1974. p. 1-36.

12. Freyre G. Casa grande \& senzala: formação da família brasileira sob o regime da economia patriarcal. 51 a ed. rev. São Paulo: Global; 2006.
13. Freyre G. Sobrados e mucambos: decadência do patriarcado rural e desenvolvimento do urbano. $14^{\mathrm{a}}$ ed. rev. São Paulo: Global; 2003.

14. DaMatta R. A casa \& a rua: espaço, cidadania, mulher e morte no Brasil. Rio de Janeiro: Brasiliense; 1985 .

15. DaMatta R. Carnavais, malandros e heróis: para uma sociologia do dilema brasileiro. 6a ed. Rio de Janeiro: Rocco; 1997.

16. Mauss M. Uma categoria do espírito humano: a noção de pessoa, a de "eu”. In: Mauss M. Sociologia e antropologia. Tradução: Paulo Neves. São Paulo: Cosac Naify; 2003. p. 367-397.

17. Bourdieu P. Da regra às estratégias. In: Bourdieu P. Coisas ditas. Tradução de Cássia R da Silveira e Denise Moreno Pegorim. Revisão técnica: Paula Montero. São Paulo: Editora Brasiliense; 1990. p. 77-95.

18. Mauss M. Ensaio sobre a dádiva. In: Mauss M. Sociologia e Antropologia com uma introdução à obra de Marcel Mauss de Claude Lévi-Strauss. Tradução de Lamberto Puccinelli. São Paulo: EPU; 1974. v. 2. p. 39-129.

19. Coelho MC. O valor das intenções: dádiva, emoção e identidade. Rio de Janeiro: Editora FGV; 2006.

20. Almeida AC. A cabeça do brasileiro. Rio de Janeiro: Record; 2007.

21. Mattos RA. Os sentidos da integralidade: algumas reflexões acerca de valores que merecem ser defendidos. In: Pinheiro R, Mattos RA, organizadores. Os sentidos da integralidade na atenção e no cuidado à saúde. $6^{\mathrm{a}}$ ed. Rio de Janeiro: IMS/UERJ Cepesc - Abrasco; 2006. p. 39-64.

Artigo apresentado em 30/08/2009

Aprovado em 21/01/2009

Versão final apresentada em 17/08/2010 